\title{
Rol de los pastizales naturales en la retención de nutrientes provenientes de la agricultura
}

\section{Role of natural grasslands in retaining nutrients from agriculture}

\author{
Lescano, Carolina (1); Ruibal, Mariana (2); Barreto, Patricia (3); Piñeiro, Verónica (3); Lozoya, Juan Pablo (4); \\ Perdomo, Carlos (3); Rodríguez-Gallego, Lorena (5) \\ (1) Ecología Funcional de Sistemas Acuáticos, Centro Universitario Regional del Este (CURE), \\ Universidad de la República (UdelaR), Uruguay. \\ (2) Licenciatura en Gestión Ambiental, Centro Universitario Regional del Este (CURE), \\ Universidad de la República (UdelaR), Uruguay. \\ (3) Departamento de Suelos y Aguas, Facultad de Agronomía, Universidad de la República (UdelaR), Uruguay. \\ (4) Centro Interdisciplinario de Manejo Costero Integrado del Cono Sur, Centro Universitario Regional del Este (CURE), \\ Universidad de la República (UdelaR), Uruguay. \\ (5) Ecología Funcional de Sistemas Acuáticos, Centro Universitario Regional del Este (CURE), \\ Universidad de la República (UdelaR), Uruguay.
}

Contacto: carolilescano@gmail.com

RECIBIDO: 5/4/2017 - APROBADO: 29/6/2017

\begin{abstract}
Resumen
La intensificación de los usos del suelo en las últimas décadas en Uruguay ha producido un aumento en la exportación de nutrientes a los cuerpos de agua, lo que explicaría el proceso de eutrofización observado en el período. La Laguna de Rocha es un sitio prioritario para la conservación por su biodiversidad, por lo que ingresó al Sistema Nacional de Áreas Protegidas. Sin embargo, no escapa a las presiones mencionadas y se han registrado ocasionalmente floraciones de cianobacterias y de macrófitas sumergidas. La cobertura vegetal en la interfase entre los cuerpos de agua y los sistemas productivos puede funcionar como zona de amortiguación, disminuyendo la carga de nutrientes provenientes de cultivos o sistemas de producción animal por escorrentía, contribuyendo a la provisión del servicio ecosistémico de mantenimiento de la calidad de agua. Mediante el uso de parcelas de escorrentía experimentales se estimó en este trabajo el servicio ecosistémico provisto por el pastizal natural de retención de nutrientes del agua de escorrentía proveniente de una pradera artificial. Se halló una retención de fosfato de 55 $\%$, nitrógeno inorgánico disuelto $44 \%$, sólidos en suspensión $28 \%$, nitrógeno total $47 \%$ y fósforo total $42 \%$. Palabras clave: Servicios ecosistémicos, calidad de agua, eutrofización, zonas buffer.
\end{abstract}

\begin{abstract}
The intensification of land uses occurred in recent decades in Uruguay had increased the exportation of nutrients to water bodies, explaining the process of eutrophication observed in this period. Laguna de Rocha is a priority site for biodiversity conservation which belongs to the National System of Protected Areas. However, the lagoon also suffered the impacts of land use changes and has registered some events of cyanobacteria and submerged macrophytes blooms. Strip areas between water bodies and agriculture can function as buffer zones, reducing the nutrient load exported from crops or livestock production systems, providing relevant ecosystem services as maintenance of water quality. With experimental runoff plots we estimated the ecosystem service of nutrients retention, provided by natural grasslands, from a field with artificial pastures. We recorded a $55 \%$ phosphate retention, $44 \%$ dissolved inorganic nitrogen, $28 \%$ suspended solids, $47 \%$ total nitrogen and $42 \%$ total phosphorus. Keywords: Ecosystem services, water quality, eutrophication, buffer zones.
\end{abstract}

\section{Introducción}

En las últimas décadas la intensificación del uso del suelo junto con nuevas formas de producción han conducido al deterioro del suelo, lo que incluye disminución del contenido de materia orgánica, pérdida de estructura, compactación y erosión (Ernst y Siri-Prieto, 2011), promoviendo la exportación de nutrientes a los cuerpos de agua (Sharpley, et al.,
1999). Asociado a esto, la incorporación de nuevas tecnologías ha aumentado los aportes de fertilizantes y plaguicidas que, por escorrentía o por infiltración, llegan a los cursos de agua o a las aguas subterráneas (Carpenter, et al., 2011).

El aumento en la carga de nutrientes en los cuerpos de agua es responsable del proceso de eutrofización que conduce al crecimiento excesivo del fitoplancton potencialmente tóxico y de la vegetación acuática, desencadenando procesos de 
deterioro del ecosistema. La descomposición de la alta carga de materia orgánica generada consume el oxígeno disuelto, lo que promueve la liberación de fósforo desde el sedimento e intensifica aún más la eutrofización (Sondergaard, et al., 2001). Estos cambios afectan en forma negativa la biodiversidad acuática, la capacidad del ecosistema de mantener la calidad del agua y, en definitiva, los usos recreacionales y de provisión de recursos que hace la sociedad de estos sistemas (Sharpley, et al., 2003; Carpenter, 2005).

En el periodo 2006-2013 la importación de fertilizantes en Uruguay aumentó de 488.000 a 1.347 .000 toneladas anuales (DIEA, 2014). Este crecimiento acompaña la tendencia de intensificación agropecuaria y la adopción de tecnologías como la siembra directa, que reducen el laboreo del suelo. $\mathrm{Si}$ bien la siembra directa reduce la erosión, se ha observado que esta práctica aumenta la pérdida de fósforo soluble (Sharpley, 2015). Resultados similares han sido reportados por Perdomo et al. (2015), quienes registraron aumentos en la pérdida de fósforo total y fósforo soluble debido a que durante la fertilización asociada a la siembra directa se enriquece el suelo más superficial, más susceptible a la erosión, pero no se incorpora el fósforo al suelo en mayor profundidad. La aplicación de $\mathrm{P}$ en el suelo por encima de las tasas a las que puede ser removido por los cultivos puede transformarse en una fuente de $P$ por escorrentía, dado que a mayor contenido de $\mathrm{P}$ en el suelo, mayor es la cantidad que se pierde por escorrentía (Pote, et al., 1996; McDowell y Sharpley, 2001). Esto explica que las medidas de manejo que se basan en aplicar dosis recomendadas son muy poco efectivas en la reducción del transporte de fósforo cuando se trabaja en fertilización asociada a la siembra directa, por lo que es recomendable incorporarlo al suelo (Perdomo, et al., 2015).

Además de las fuentes de nutrientes, se deben considerar los factores que afectan su transporte (Sharpley, et al., 2003). En este sentido, un aumento del transporte puede estar vinculado al manejo del suelo mediante prácticas que favorecen la erosión, así como al efecto del cambio climático sobre la intensidad y frecuencia de las tormentas (Jeppesen, et al., 2009; Moss, et al., 2011).

La Laguna de Rocha presenta una alta productividad pesquera (Fabiano y Santana, 2006) y alberga una gran biodiversidad, y es por esto considerada área prioritaria para la conservación (Brazeiro, et al., 2008). En 2010 se declaró Paisaje Protegido del Sistema Nacional de Áreas Protegidas y en 2016 se aprobó su Plan de Manejo. Sus tributarios reciben el aporte puntual de efluentes industriales, el vertido de la planta de tratamiento de efluentes domiciliarios de la ciudad de Rocha, que cuenta con 25.500 habitantes (Instituto Nacional de Estadística, 2011), y el aporte difuso de actividades agrícolas y ganaderas de toda la cuenca. Los mayores usos del suelo de la cuenca son ganadería extensiva, predominantemente sobre campo natural (mayor a 60\% en 2011; Nin, et al., 2016), forestación y agricultura.

El área destinada a agricultura en la cuenca casi se duplicó en el período 1974-2011, pasando de 6.486 ha en 1974 (Rodríguez-Gallego, et al., 2017), a 11.000 ha en 2011 (Nin, et al., 2016). La forestación industrial comenzó en la zona a partir de 2006 y en 2011 alcanzó el 7,5\% de la cuenca, mientras que el área de pastizales se redujo un 10 \% (Rodríguez-Gallego, et al., 2017). En 2005 el aporte estimado de nutrientes desde la cuenca a la laguna fue del entorno de $4 \mathrm{~kg} / \mathrm{anno} / \mathrm{ha}$ de nitrógeno y $0,7 \mathrm{~kg} / \mathrm{año} / \mathrm{ha}$ de fósforo (Rodríguez-Gallego, et al., 2017). Acompañando la intensificación de usos del suelo, se observaron desde 1997 algunos síntomas de eutrofización, con aumentos en la concentración de fósforo total, fósforo reactivo soluble y clorofila $a$ (Aubriot, et al., 2005), y recientemente algunos episodios de floraciones de cianobacterias y proliferaciones de plantas sumergidas (Rodríguez-Gallego, et al., 2010, 2015). Por su parte, Cabrera (2015), mediante el desarrollo de un modelo hidrodinámico acoplado a un modelo de calidad de agua, estimó el umbral de fósforo reactivo soluble necesario para el crecimiento de cianobacterias en la laguna (25-45 ug/l), indicando que el aporte en la actualidad se encontraría en valores cercanos al umbral estimado para su crecimiento.

Nin et al. (2016) estimaron el nivel de provisión de servicios ecosistémicos en la cuenca de la Laguna de Rocha mediante una modelación espacial multi-atributo. De los servicios ecosistémicos evaluados, el que mostró el mayor valor medio de provisión y el que se vería más reducido en un contexto de expansión agrícola y forestal fue el de prevención de la eutrofización.

Las zonas buffer (ZB) se definen como bandas de vegetación nativa o implantada ubicada pendiente abajo de cultivos o de instalaciones para producción animal, como tambos o feedlots (Dillaha, et al., 1988), o zonas de vegetación permanente en la interfase entre los campos y cuerpos de agua a los que estos drenan (Abu-Zreig, et al., 2003). Por encontrarse en esta interfase pueden modificar, incorporar, diluir o concentrar sustancias antes de que ingresen al curso de agua, actuando como filtro para fuentes difusas de contaminación del agua (Magette, et al., 1989; Deng, et al., 2011), reduciendo la velocidad de flujo y la sedimentación y favoreciendo la retención de nutrientes y su uso por parte de la vegetación y los microorganismos (Osborne y Kovacic, 1993; Sabater, et al., 2003; Hoffmann, et al., 2009). Mediante estos mecanismos proporcionan un importante servicio ecosistémico (SE) de regulación (Millennium Ecosystem Assessment, 2003) de mantenimiento de la calidad de agua y reducción de la eutrofización. Ejemplos de ZB son el bosque ribereño, los humedales y el campo natural en zonas bajas. Algunos autores incluyen a los propios cultivos como ZB (Young, et al., 1980).

Los diseños metodológicos más usados para evaluar la eficiencia de las ZB para reducir nutrientes comparan concentración, volumen de escorrentía y carga de nutrientes o sedimentos (determinada por el producto de la concentración y el volumen de escorrentía). Los diseños para la obtención de estos datos dependen del tipo de nutriente analizado debido a que se comportan diferente en el ambiente. El fósforo es un nutriente muy poco soluble, que en su mayor parte está unido a pequeñas partículas del suelo, constituyendo el fósforo particulado. Una menor parte se desplaza en forma disuelta como fósforo reactivo soluble (PRS) y otra como fósforo total disuelto, que está principalmente asociado a compuestos orgánicos disueltos pero no está biodisponible. Esto determina que el fósforo mayormente se transporte unido a partículas, por lo que se lo analiza en agua que escurre superficialmente (por ejemplo, mediante el uso de parcelas de escorrentía). A diferencia del fósforo, el nitrógeno se encuentra en gran parte disuelto, en sus formas de amonio $\left(\mathrm{NH}_{4}\right)$, nitrito $\left(\mathrm{NO}_{2}\right)$ y nitrato $\left(\mathrm{NO}_{3}\right)$. Por ello una gran parte se desplaza en forma disuelta, lo que le permite infiltrar el suelo y alcanzar el agua subsuperficial y profunda (Naiman, et al., 2005), y por esto se colecta mayormente utilizando dispositivos como lisímetros y piezómetros. 
Los estudios relacionados a la función de las ZB comenzaron en la década de 1960 y se han enfocado en determinar su capacidad de retención de nutrientes y sedimentos (Peterjohn y Correll, 1984; Lowrance, et al., 1984; Wilson, 1967), el ancho de ZB apropiado para esa retención, cómo se modifica con la pendiente y tipo de suelo, el tipo de vegetación más apropiada para la retención (Aguiar, et al., 2015; Abu-Zreig, et al., 2003; Daniels y Gilliam, 1996; Osborne y Kovacic, 1993; Young, et al., 1980), y la relación que se debe establecer entre al área de ZB respecto al área de cultivo (Zhou, et al., 2014; Al-wadaey, et al., 2012).

En este trabajo se analiza experimentalmente la retención de nutrientes en una ZB de un predio agrícola ganadero en la cuenca de la Laguna de Rocha. Como hipótesis general se plantea que el campo natural que se encuentra en la interfase entre la pradera artificial y los cursos de agua intermitentes actúa como $\mathrm{ZB}$, reteniendo nutrientes que serían aportados por la pradera artificial.

\section{Materiales y Métodos}

\section{Área de estudio}

El sitio de estudio se ubica en un predio en la llanura media de la Laguna de Rocha dentro del Paisaje Protegido (Figura 1). Tiene una pendiente de 3,5\% y suelos que corresponden a la Unidad José Pedro Varela (MGAP, 1976). El trabajo de campo se llevó a cabo de julio a diciembre de 2014. El predio cuenta con una pradera artificial que se sembró por siembra directa en 2013, refertilizada cada año, compuesta por achicoria (Cichorium intybus), trébol rojo (Trifolium pratense) y trébol blanco (Trifolium repens). Los cursos de agua son intermitentes y en el campo natural que los rodea se encuentran especies de gramíneas nativas y algunas especies indicadoras de mayor humedad en suelo, como redondita de agua (Hydrocotile bonariensis). El pastizal natural forma un cinturón que rodea a la pradera artificial en las zonas bajas, con una cobertura vegetal del $100 \%$, de más de $10 \mathrm{~cm}$ de altura, actuando de interfase entre el cultivo y los cursos de agua intermitentes. El área de trabajo se cercó con alambrado eléctrico y de púas para evitar el ingreso de ganado.

\section{Estimación experimental de la retención de nutrientes por una zona riparia}

Se colocaron 12 parcelas de escorrentía de acuerdo a Perdomo et al. (2015) y Vadas et al. (2005) en el sitio de estudio. El diseño experimental consistió en tres parcelas control en la zona de pradera artificial y tres parcelas control en la zona de pastizal. Además, se instalaron seis parcelas a modo de tratamiento (parcelas mixtas), que abarcaban una superficie igual de pradera artificial y de pastizal. De esta manera se abarcó la zona de transición entre el cultivo y la ZB. A tres de estas parcelas se les cortó el pastizal con tijera, simulando el efecto del pastoreo del ganado, manteniendo siempre una altura mayor a $5 \mathrm{~cm}$ de la vegetación (Figura 2).

Las parcelas (Figura 3) consistieron en un borde de chapa, enterrado $5 \mathrm{~cm}$ en el suelo y sobresaliendo $10 \mathrm{~cm}$, delimitando una porción de suelo de 1,5 m x 1,5 m (controles) y 1,5 m x $3 \mathrm{~m}$ de largo (mixtas, doble de tamaño que las controles). El agua de escorrentía colectada durante la lluvia dentro de cada parcela se vertía en dos baldes de 20 litros conectados a través de un sistema de cañerías. El sistema incluía un contador de volumen para registrar el caudal excedente que no era retenido en los baldes. Los baldes se taparon para evitar el ingreso de agua de lluvia de forma directa. Dado el dudoso funcionamiento de algunos contadores de flujo de las parcelas y la gran variabilidad de los datos de volumen de escorrentía obtenidos, se descartaron esos datos. En su lugar, para estimar la escorrentía se utilizó el método del Número de Curva (NC) (USDA, 1985). Este modelo determina el valor de escurrimiento según la precipitación, grupo hidrológico del suelo, uso y tratamiento del suelo y cobertura. Para este cálculo se utilizaron datos del registro pluviométrico obtenido de la estación meteorológica de Rocha (los datos fueron solicitados mediante nota al Instituto Nacional de Meteorología). Mediante el uso de tablas incorporadas al modelo, se corrigieron los valores de escurrimiento por la condición de humedad
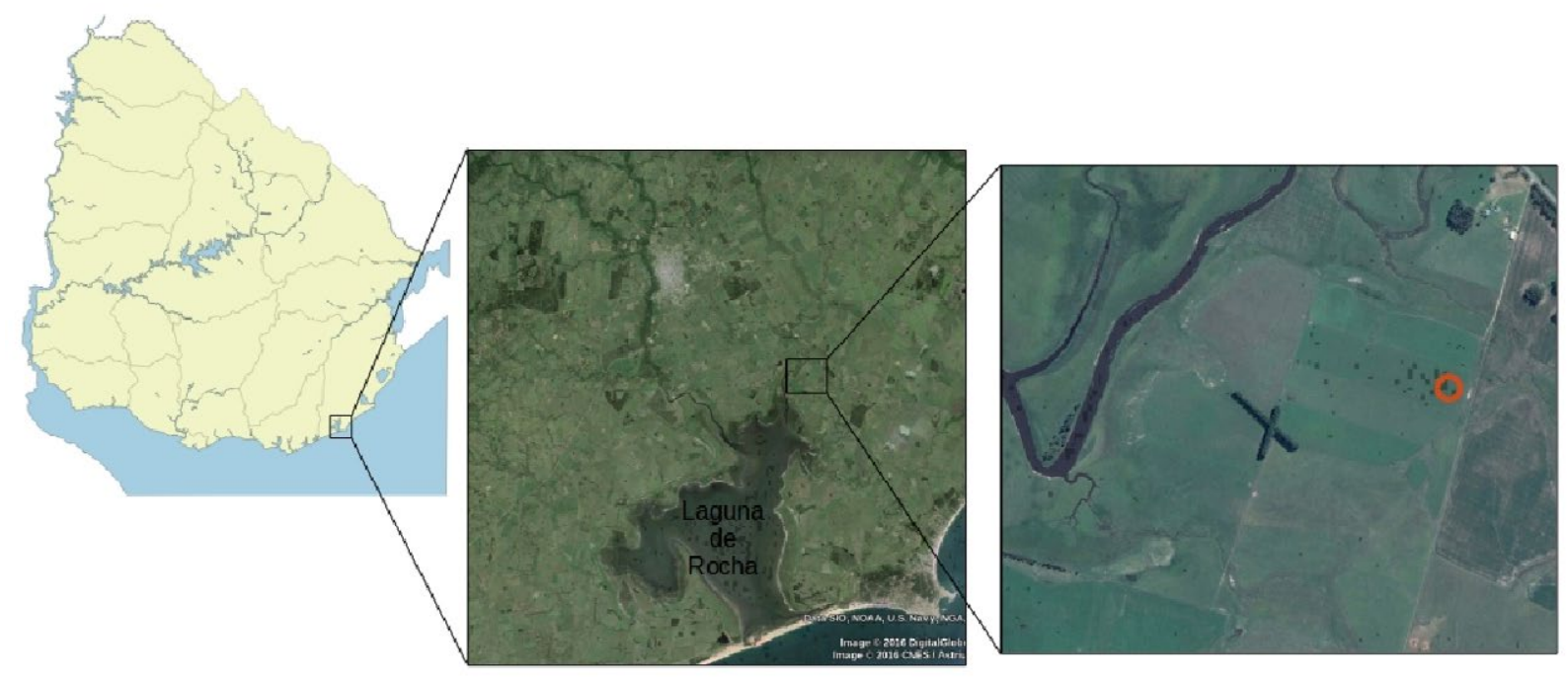

Figura 1. Esquema de ubicación del sitio de estudio en el Paisaje Protegido Laguna de Rocha (Rocha, Uruguay). El círculo anaranjado representa la ubicación de las parcelas de escorrentía. 


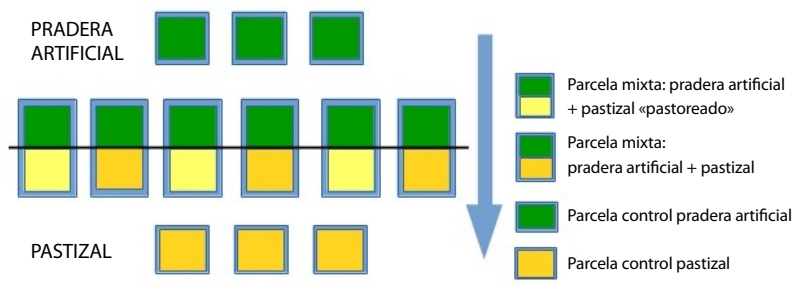

Figura 2. Esquema del diseño experimental. La flecha indica el sentido de la escorrentía.

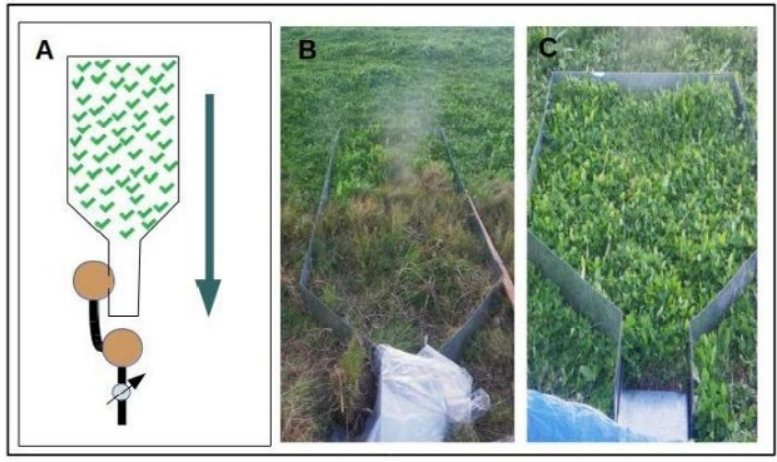

Figura 3. Parcelas de escorrentía. A) Esquema de parcela. La flecha indica el sentido de la pendiente. Los círculos marrones representan los baldes de recolección del agua de escorrentía. En la parte inferior del esquema se representa un medidor de volumen del agua que sale de los baldes. B) y C) Fotografías de parcela mixta y parcela con pradera artificial, respectivamente.

antecedente del suelo en los cinco días previos al evento de precipitación y según la estación del año en la que ocurrió.

El volumen de escorrentía se estimó para los tratamientos pradera artificial y pastizal en los siete eventos en los que se colectó agua. Para las parcelas mixtas, que cuentan con igual superficie de pradera artificial y pastizal se realizó un promedio del volumen estimado para esos tratamientos.

Durante seis meses se muestreó el agua de cada parcela luego de 12-24 horas de ocurrido cada evento importante de lluvias $(>10 \mathrm{~mm})$. El agua recogida en los baldes de cada parcela fue mezclada, se tomó una muestra en botellas y se congelaron para su preservación hasta realizar los análisis químicos de nutrientes en el laboratorio. Se analizaron los siguientes nutrientes: fósforo total (PT; Valderrama, 1981; Murphy y Riley, 1962), nitrógeno total (NT; Valderrama, 1981 y Müller y Widemann, 1955), nitrato $\left(\mathrm{NO}_{3}\right.$; Müller y Widemann, 1955), nitrito $\left(\mathrm{NO}_{2}\right.$; Bendschneider y Robinson, 1952), amonio $\left(\mathrm{NH}_{4}\right.$; Koroleff, 1970) y fósforo reactivo soluble (PRS; Murphy y Riley, 1962). También se cuantificaron los sólidos en suspensión (SS; American Public Health Association, 1985).

El nitrógeno inorgánico disuelto (NID) se define como la suma de la concentración de $\mathrm{NO}_{3}, \mathrm{NO}_{2}$ y $\mathrm{NH}_{4}$. La carga de nutrientes se obtuvo multiplicando la concentración de nutrientes hallada para cada parcela en cada evento de lluvia, por el volumen de escorrentía para ese tratamiento y evento estimado por el método de NC, y se corrigió por el tamaño de la parcela. La carga acumulada de nutrientes por tratamiento se definió como el promedio de la suma de cargas para cada nutriente obtenida por parcela a lo largo de todo el período estudiado.
Dado que las parcelas mixtas cuentan con una zona de aporte de nutrientes de pradera artificial y una ZB de pastizal, la diferencia entre la carga acumulada por parcelas de pradera artificial y el promedio de la carga acumulada por parcelas mixta y mixta cortada se consideró como una medida de la retención de nutrientes. Ese valor pasado a porcentaje se denominó porcentaje de retención y fue calculado para SS, nutrientes totales y disueltos.

Para analizar las diferencias del aporte de nutrientes entre los tratamientos se utilizó el test de Kruskal-Wallis para cada evento (estadístico X), dado que no requiere normalidad de las muestras y es suficientemente robusto a la heterocedasticidad (Zar, 1999). Para los eventos en los que el test de Kruskal-Wallis presentó diferencias estadísticamente significativas se aplicó el test de Mann-Whitney (estadístico t) para detectar diferencias entre pares de tratamientos. Para evaluar la correlación entre concentración de diferentes nutrientes y SS se realizaron análisis de correlación de Spearman (estadístico $\rho)$. Los análisis se realizaron con R Commander versión 2.0-3 y los gráficos con SigmaPlot 12.0.

La biomasa vegetal total para cada tratamiento se estimó en tres momentos a lo largo del período de estudio. Para ello se tomaron muestras de la vegetación adyacente a las parcelas en cuadrantes de $50 \times 50 \mathrm{~cm}$, donde la vegetación contenida en el cuadrante se cortó con tijera a $5 \mathrm{~cm}$ del suelo. La biomasa cosechada se secó en estufa a $70-80^{\circ} \mathrm{C}$ por 48 horas y se estimó el peso seco en $\mathrm{g} \mathrm{PS} / \mathrm{m}^{2}$.

Se tomaron 12 muestras de suelo en la zona de pastizal y en la zona de pradera artificial, con taladro, separando en $\operatorname{los} 7 \mathrm{~cm}$ más superficiales y los $7 \mathrm{~cm}$ siguientes. Se analizó el P mediante la técnica de $\mathrm{P}$ Bray 1, al inicio y al final de los experimentos.

\section{Resultados}

Los resultados del análisis de $\mathrm{P}$ en suelo (P Bray 1) al inicio del trabajo de campo fueron 5 ppm en la zona de pastizal y 7 ppm en la zona de pradera.

La biomasa total al inicio del estudio presentó valores similares entre tratamientos, del entorno de $50 \mathrm{~g} \mathrm{PS} / \mathrm{m}^{2}$ (Figura 4). A partir de entonces se observó un aumento de la biomasa total para todos los tratamientos, pero el crecimiento fue mayor para la pradera artificial y menor para el pastizal. La parcela mixta presentó un valor intermedio o cercano al de pastizal, pero en el caso de la parcela mixta cortada, el valor final de biomasa total fue menor al de pastizal. Si bien en diciembre la biomasa de pradera artificial resultó mayor

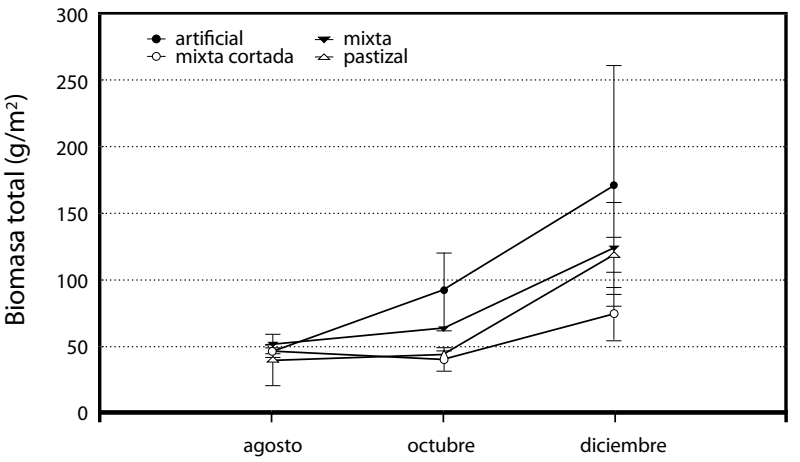

Figura 4. Biomasa total de la vegetación en el período de estudio. 


\begin{tabular}{|l|c|c|c|c|c|c|c|}
\hline Mes & Jul18 & Ago3 & Set11 & Set16 & Oct17 & Nov4 & Dic3 \\
\hline Precipitación $(\mathrm{mm})$ & 16 & 34 & 40 & 89 & 18 & 56 & 52 \\
Escurrimiento pastizal $\left(1 . \mathrm{m}^{-2}\right)$ & 0 & 0 & 4 & 29 & 0 & 2 & 2 \\
Escurrimiento pradera artificial $\left(\mathrm{l} . \mathrm{m}^{-2}\right)$ & 0 & 0 & 9 & 41 & 1 & 7 & 8 \\
Escurrimiento mixtas $\left(1 . \mathrm{m}^{-2}\right)$ & 0 & 0 & 6,5 & 35 & 0,5 & 4,5 & 5 \\
\hline
\end{tabular}

Tabla 1. Volumen de escorrentía calculado según el método del $\mathrm{NC}$ en $\mathrm{lm}^{-2}$ para cada uno de los eventos de lluvia analizados.
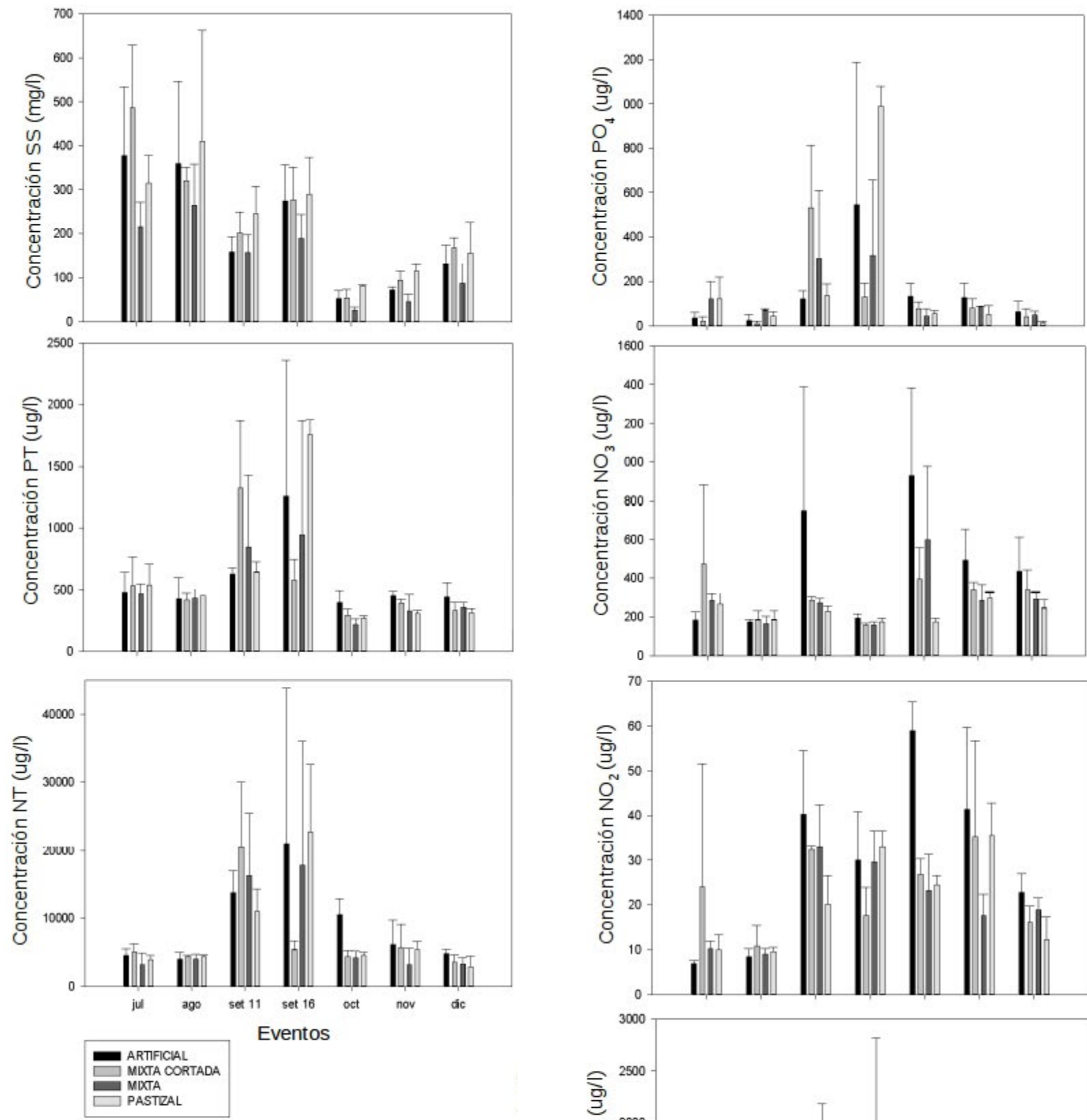

Figura 5. Concentración de sólidos en suspensión, nutrientes totales y disueltos para los siete eventos en los que se colectó agua.
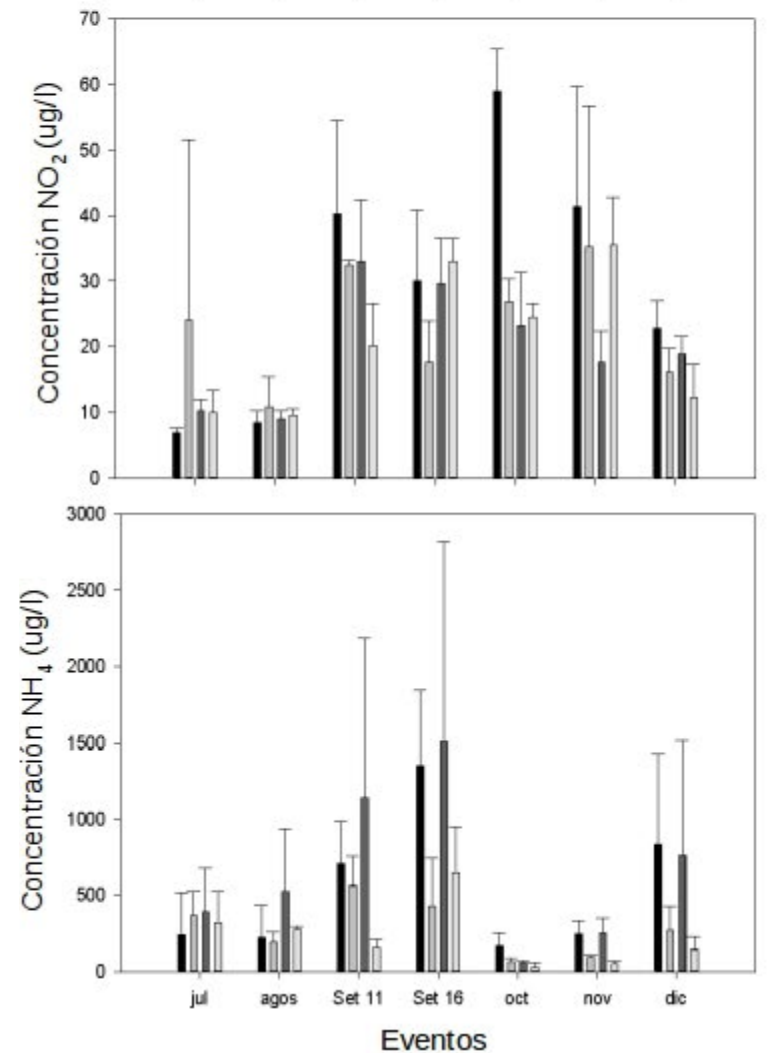
que la de pastizal, es de destacar que se distribuía en altura con baja cobertura a ras del suelo, mientras que el pastizal se disponía con mayor densidad desde la superficie del suelo.

Todos los eventos de lluvia analizados tuvieron un volumen de escorrentía suficiente para colectar agua en los baldes. Sin embargo, el volumen de escorrentía estimado mediante el método del NC mostró valores de cero $\mathrm{lm}^{-2}$ para los eventos registrados en julio y agosto, mientras que en el resto de los eventos de lluvia el modelo cuantificó escorrentía (Tabla 1). Las parcelas mixtas con y sin "pastoreo» tuvieron valores de escorrentía intermedios respecto a las parcelas control.

\section{Concentración de SS y nutrientes}

Se observó variabilidad evento a evento y no se observaron diferencias significativas entre tratamientos para concentración de SS, PT y NT. Las concentraciones medias obtenidas para el NT mostraron un perfil similar a las de PT, pero con valores un orden de magnitud mayores, con un índice de correlación de Spearman moderado $\left(\rho=0,57, p=1,5 \mathrm{e}^{-8}\right)$. Los valores elevados de NT y PT registrados en setiembre coincidieron con lluvias importantes y alta humedad antecedente. La concentración de SS mostró una correlación positiva moderada con la concentración de PT $\left(\rho=0,53, p=3,4 \mathrm{e}^{-7}\right)$, al igual que la correlación entre
$\mathrm{PO}_{4}$ y PT $\left(\rho=0,68, \mathrm{p}=2,3 \mathrm{e}^{-12}\right)$, mientras que la concentración de NT y NID resultó en un índice de correlación menor $(\rho=$ $\left.0,45, p=2,2 \mathrm{e}^{-5}\right)$. Si bien la concentración de nutrientes disueltos mostró variabilidad, para el caso de $\mathrm{NO}_{3}$ y $\mathrm{NO}_{2}$ presentó en general valores más elevados en parcelas con pradera artificial, seguidos de mixtas y luego pastizal (Figura 5).

\section{Carga de SS y nutrientes}

En los eventos de julio y agosto la carga de nutrientes y SS fue cero dado que el volumen de escorrentía estimado por el modelo del NC fue cero $\mathrm{lm}^{-2}$. La carga de SS fue siempre mayor en la pradera artificial que en el resto de los tratamientos (Figura 6, izquierda). La carga estimada de PT y NT mostró valores mayores en la parcela con pradera artificial que en la de pastizal. Para los eventos de octubre, noviembre y diciembre la carga de SS, PT y NT de las parcelas mostró un descenso desde la pradera artificial, mixta cortada, mixta y pastizal. Estas diferencias resultaron estadísticamente significativas (Tabla 2) en octubre, noviembre y diciembre para SS y para PT, así como en octubre y diciembre para NT. Se observaron valores más elevados de SS, PT y NT para el evento del 16 de setiembre, en el que se registraron precipitaciones de $89 \mathrm{~mm}$.

\begin{tabular}{|c|c|c|c|c|}
\hline & Evento & Kruskal-Wallis & & Mann-Whitney \\
\hline \multirow{3}{*}{ carga SS } & oct & $X=10.53 ; p=0.015$ & $\begin{array}{l}\text { artificial-mixta } \\
\text { artificial-pastizal } \\
\text { mixta cortada-pastizal } \\
\text { mixta-pastizal }\end{array}$ & $\begin{array}{l}t=3.820 ; p=0.019 \\
t=5.130 ; p=0.007 \\
t=5.116 ; p=0.007 \\
t=6.571 ; p=0.003\end{array}$ \\
\hline & nov & $X=8.64 ; p=0.035$ & $\begin{array}{l}\text { artificial-mixta } \\
\text { artificial-pastizal } \\
\text { mixta cortada-pastizal } \\
\text { mixta cortada-mixta }\end{array}$ & $\begin{array}{l}t=6.008 ; p=0.004 \\
t=8.210 ; p=0.001 \\
t=3.514 ; p=0.025 \\
t=3.277 ; p=0.031\end{array}$ \\
\hline & dic & $X=8.64 ; p=0.035$ & $\begin{array}{l}\text { artificial-pastizal } \\
\text { mixta cortada-pastizal }\end{array}$ & $\begin{array}{l}\mathrm{t}=3.547 ; \mathrm{p}=0.024 \\
\mathrm{t}=5.067 ; \mathrm{p}=0.007\end{array}$ \\
\hline \multirow{3}{*}{ carga PT } & oct & $X=9.98 ; p=0.019$ & $\begin{array}{l}\text { artificial-mixta cortada } \\
\text { artificial-mixta } \\
\text { artificial-pastizal } \\
\text { mixta cortada-pastizal } \\
\text { mixta-pastizal }\end{array}$ & $\begin{array}{l}\mathrm{t}=4.454 ; \mathrm{p}=0.011 \\
\mathrm{t}=5.141 ; \mathrm{p}=0.007 \\
\mathrm{t}=7.254 ; \mathrm{p}=0.002 \\
\mathrm{t}=10.473 ; \mathrm{p}=<0.001 \\
\mathrm{t}=8.521 ; \mathrm{p}=0.001\end{array}$ \\
\hline & nov & $X=9.43 ; p=0.024$ & $\begin{array}{l}\text { artificial-mixta } \\
\text { artificial-mixta cortada } \\
\text { artificial-pastizal } \\
\text { mixta cortada-pastizal }\end{array}$ & $\begin{array}{l}t=4.475 ; p=0.011 \\
t=8.933 ; p=<0.001 \\
t=15.767 ; p=<0.001 \\
t=15.767 ; p=<0.001\end{array}$ \\
\hline & dic & $X=9.36 ; p=0.025$ & $\begin{array}{l}\text { artificial-mixta cortada } \\
\text { artificial-mixta } \\
\text { mixta cortada-pastizal } \\
\text { mixta-pastizal }\end{array}$ & $\begin{array}{l}t=3.451 ; p=0.026 \\
t=3.368 ; p=0.028 \\
t=5.335 ; p=0.006 \\
t=8.796 ; p=<0.001\end{array}$ \\
\hline \multirow[t]{2}{*}{ carga NT } & oct & $X=9.51 ; p=0.023$ & $\begin{array}{l}\text { artificial-mixta cortada } \\
\text { artificial-mixta } \\
\text { artificial-pastizal } \\
\text { mixta-pastizal } \\
\text { mixta cortada-pastizal }\end{array}$ & $\begin{array}{l}t=6.010 ; p=0.004 \\
t=6.051 ; p=0.004 \\
t=7.720 ; p=0.002 \\
t=7.610 ; p=0.002 \\
t=8.384 ; p=0.001\end{array}$ \\
\hline & dic & $X=9.36 ; p=0.025$ & $\begin{array}{l}\text { artificial-mixta cortada } \\
\text { mixta cortada-pastizal } \\
\text { mixta-pastizal } \\
\text { artificial-pastizal }\end{array}$ & $\begin{array}{l}\mathrm{t}=4.801 ; \mathrm{p}=0.009 \\
\mathrm{t}=3.196 ; \mathrm{p}=0.033 \\
\mathrm{t}=3.205 ; \mathrm{p}=0.033 \\
\mathrm{t}=9.747 ; \mathrm{p}=<0.001\end{array}$ \\
\hline
\end{tabular}

Tabla 2. Significancia estadística de retención de sólidos en suspensión y nutrientes totales: carga de sólidos en suspensión (SS), fósforo total (PT) y nitrógeno total (NT). 

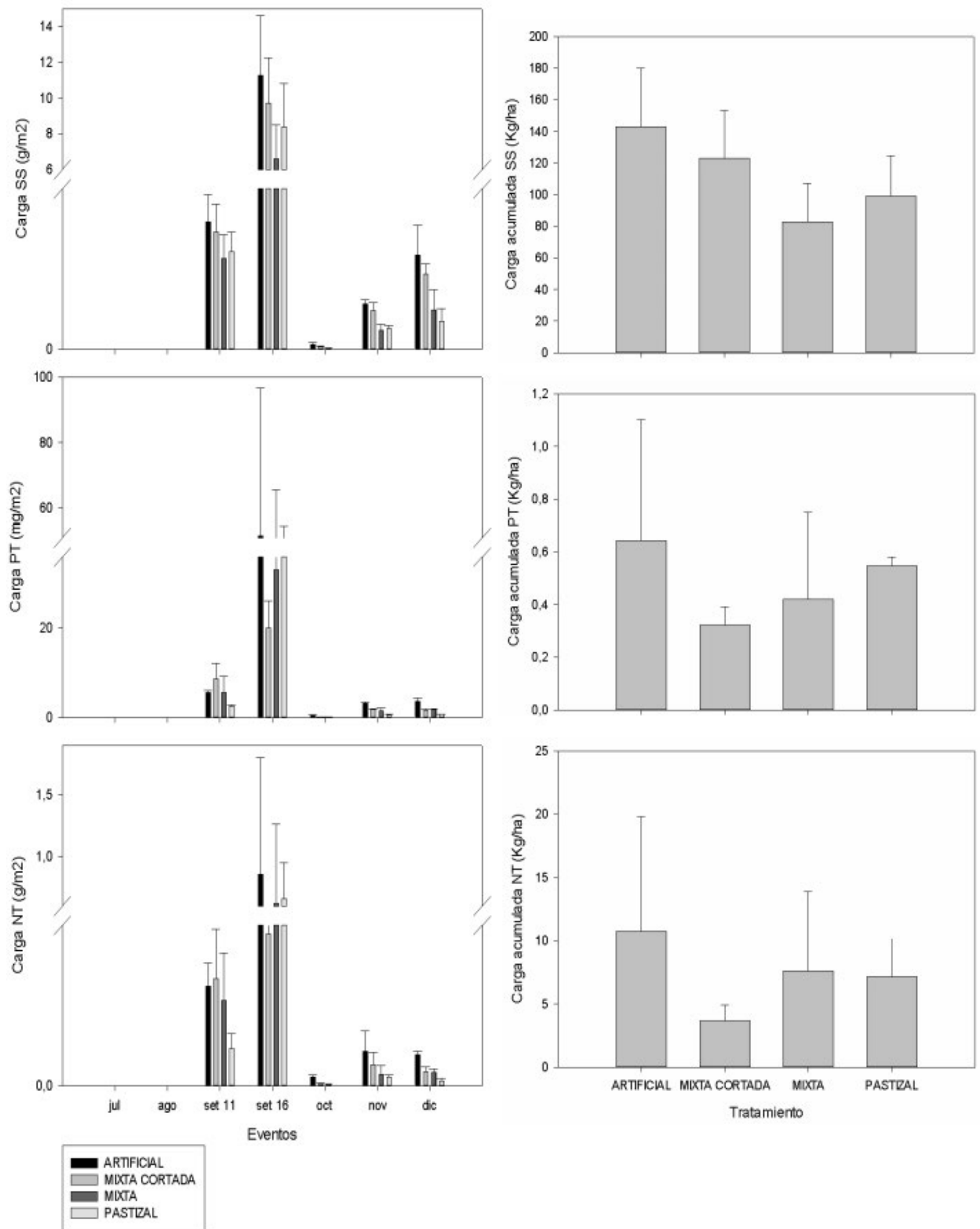

Figura 6. Carga de SS, PT y NT para los cinco eventos de precipitación. La escorrentía se estimó por el método del NC (izquierda). Carga acumulada en el período de estudio (seis meses) de SS, PT y NT (derecha).

La carga acumulada promedio para SS, PT y NT fue mayor en la pradera artificial que en el resto de los tratamientos (Figura 6, derecha). La retención de SS, PT y NT para el período estudiado fue de 28,42 y $47 \%$, respectivamente. Tanto para PT como para NT la carga acumulada promedio para la pradera artificial y parcela mixta mostró desvíos estándar mayores que mixta cortada y pastizal, debido a los grandes desvíos en los valores de carga del evento del 16 de setiembre. Las diferencias de carga acumulada de SS, PT y NT entre tratamientos no fueron significativas.

El $\mathrm{PO}_{4}$ mostró variabilidad de la carga evento a evento, con valores mayores para el evento de mayor precipitación 


\begin{tabular}{|c|c|c|c|c|}
\hline & Evento & Kruskal-Wallis & & Mann-Whitney \\
\hline \multirow[t]{2}{*}{ carga $\mathrm{PO}_{4}$} & oct & $X=9.839 ; p=0.020$ & $\begin{array}{l}\text { artificial-mixta } \\
\text { artificial-pastizal } \\
\text { mixta cortada-pastizal }\end{array}$ & $\begin{array}{l}\mathrm{t}=3.132 ; \mathrm{p}=0.035 \\
\mathrm{t}=3.903 ; \mathrm{p}=0.017 \\
\mathrm{t}=4.360 ; \mathrm{p}=0.012\end{array}$ \\
\hline & nov & $\mathrm{X}=8.744 ; \mathrm{p}=0.033$ & $\begin{array}{l}\text { artificial-pastizal } \\
\text { mixta-pastizal }\end{array}$ & $\begin{array}{l}\mathrm{t}=2.971 ; \mathrm{p}=0.041 \\
\mathrm{t}=6.182 ; \mathrm{p}=0.003\end{array}$ \\
\hline \multirow{4}{*}{ carga $\mathrm{NO}_{3}$} & set11 & $X=9.430 ; p=0.024$ & $\begin{array}{l}\text { mixta cortada-pastizal } \\
\text { mixta-pastizal }\end{array}$ & $\begin{array}{l}t=9.987 ; p=<0.001 \\
t=8.153 ; p=0.001\end{array}$ \\
\hline & oct & $\mathrm{X}=9.024 ; \mathrm{p}=0.029$ & $\begin{array}{l}\text { artificial-mixta cortada } \\
\text { artificial-pastizal } \\
\text { mixta cortada-pastizal }\end{array}$ & $\begin{array}{l}\mathrm{t}=2.772 ; \mathrm{p}=0.050 \\
\mathrm{t}=3.572 ; \mathrm{p}=0.023 \\
\mathrm{t}=4.209 ; \mathrm{p}=0.014\end{array}$ \\
\hline & nov & $X=9.667 ; p=0.022$ & $\begin{array}{l}\text { artificial-mixta cortada } \\
\text { mixta cortada-pastizal } \\
\text { artificial-mixta } \\
\text { artificial-pastizal } \\
\text { mixta-pastizal }\end{array}$ & $\begin{array}{l}t=2.945 ; p=0.042 \\
t=8.976 ; p=<0.001 \\
t=3.194 ; p=0.033 \\
t=4.428 ; p=0.011 \\
t=3.262 ; p=0.031\end{array}$ \\
\hline & dic & $X=9.430 ; p=0.024$ & $\begin{array}{l}\text { artificial-pastizal } \\
\text { mixta cortada-pastizal } \\
\text { mixta-pastizal }\end{array}$ & $\begin{array}{l}t=3.665 ; p=0.021 \\
t=4.051 ; p=0.015 \\
t=8.145 ; p=0.001\end{array}$ \\
\hline \multirow{3}{*}{ carga $\mathrm{NO}_{2}$} & set11 & $X=8.744 ; p=0.033$ & $\begin{array}{l}\text { artificial-pastizal } \\
\text { mixta-pastizal }\end{array}$ & $\begin{array}{l}t=3.738 ; p=0.020 \\
t=3.478 ; p=0.025\end{array}$ \\
\hline & oct & $\mathrm{X}=9.492 ; \mathrm{p}=0.023$ & $\begin{array}{l}\text { artificial-mixta cortada } \\
\text { artificial-mixta } \\
\text { artificial-pastizal } \\
\text { mixta cortada-pastizal } \\
\text { mixta-pastizal }\end{array}$ & $\begin{array}{l}\mathrm{t}=11.962 ; \mathrm{p}=<0.001 \\
\mathrm{t}=10.922 ; \mathrm{p}=<0.001 \\
\mathrm{t}=16.076 ; \mathrm{p}=<0.001 \\
\mathrm{t}=13.113 ; \mathrm{p}=<0.001 \\
\mathrm{t}=5.050 ; \mathrm{p}=0.007\end{array}$ \\
\hline & dic & $X=9.667 ; p=0.022$ & $\begin{array}{l}\text { artificial-mixta cortada } \\
\text { artificial-mixta } \\
\text { mixta cortada-pastizal } \\
\text { mixta-pastizal } \\
\text { artificial-pastizal }\end{array}$ & $\begin{array}{l}t=4.679 ; p=0.009 \\
t=4.296 ; p=0.013 \\
t=4.675 ; p=0.009 \\
t=7.264 ; p=0.002 \\
t=7.938 ; p=0.001\end{array}$ \\
\hline \multirow{2}{*}{ carga $\mathrm{NH}_{4}$} & oct & $X=9.565 ; p=0.023$ & $\begin{array}{l}\text { artificial-mixta cortada } \\
\text { artificial-mixta } \\
\text { artificial-pastizal } \\
\text { mixta cortada-pastizal } \\
\text { mixta-pastizal }\end{array}$ & $\begin{array}{l}\mathrm{t}=2.878 ; \mathrm{p}=0.045 \\
\mathrm{t}=2.972 ; \mathrm{p}=0.041 \\
\mathrm{t}=3.595 ; \mathrm{p}=0.023 \\
\mathrm{t}=5.897 ; \mathrm{p}=0.004 \\
\mathrm{t}=7.364 ; \mathrm{p}=0.002\end{array}$ \\
\hline & nov & $X=9.667 ; p=0.022$ & $\begin{array}{l}\text { artificial-mixta cortada } \\
\text { artificial-pastizal } \\
\text { mixta-pastizal } \\
\text { mixta cortada-pastizal }\end{array}$ & $\begin{array}{l}\mathrm{t}=3.993 ; \mathrm{p}=0.016 \\
\mathrm{t}=4.933 ; \mathrm{p}=0.008 \\
\mathrm{t}=3.965 ; \mathrm{p}=0.017 \\
\mathrm{t}=8.701 ; \mathrm{p}=<0.001\end{array}$ \\
\hline \multicolumn{2}{|c|}{ carga acumulada $\mathrm{NO}_{3}$} & $\mathrm{X}=9.359 ; \mathrm{p}=0.025$ & $\begin{array}{l}\text { artificial-mixta } \\
\text { artificial-pastizal } \\
\text { mixta cortada-pastizal } \\
\text { mixta-pastizal }\end{array}$ & $\begin{array}{l}\mathrm{t}=2.852 ; \mathrm{p}=0.046 \\
\mathrm{t}=3.627 ; \mathrm{p}=0.022 \\
\mathrm{t}=5.161 ; \mathrm{p}=0.007 \\
\mathrm{t}=5.477 ; \mathrm{p}=0.005\end{array}$ \\
\hline \multicolumn{2}{|c|}{ carga acumulada $\mathrm{NO}_{2}$} & $X=8.128 ; p=0.043$ & $\begin{array}{l}\text { artificial-mixta cortada } \\
\text { artificial-pastizal }\end{array}$ & $\begin{array}{l}\mathrm{t}=2.807 ; \mathrm{p}=0.048 \\
\mathrm{t}=2.849 ; \mathrm{p}=0.046\end{array}$ \\
\hline
\end{tabular}

Tabla 3. Significancia estadística de retención de nutrientes disueltos. Carga de fosfato $\left(\mathrm{PO}_{4}\right)$, nitrato $\left(\mathrm{NO}_{3}\right)$, nitrito $\left(\mathrm{NO}_{2}\right)$ y amonio $\left(\mathrm{NH}_{4}\right)$ y carga acumulada de nitrato y nitrito.

registrado en el período ( 16 de setiembre). Para los eventos de octubre, noviembre y diciembre se observó una carga media mayor en la pradera artificial, seguida de las parcelas mixtas y, por último, el pastizal. La carga de $\mathrm{NO}_{3}, \mathrm{el} \mathrm{NO}_{2} \mathrm{y} \mathrm{NH}_{4}$ presentó en general valores más altos para pradera artificial, seguido de parcelas mixtas y luego pastizal (Tabla 3, Figura 7, izquierda).

$\mathrm{El} \mathrm{PO}_{4}$ presentó un valor de carga acumulada mayor en las parcelas de pastizal, seguido de las de pradera artificial, y luego las parcelas mixtas. Las diferencias entre tratamientos no fueron significativas. $\mathrm{El} \mathrm{NO}_{3}$ mostró una carga acumulada mayor en la pradera artificial, seguida de las parcelas mixtas y luego las parcelas de pastizal. Las diferencias entre tratamientos resultaron significativas. Comparando entre pares de tratamientos, las diferencias resultaron estadísticamente significativas entre pradera artificial y mixta, pradera artificial y pastizal, mixta cortada y pastizal, y entre mixta y pastizal (Tabla 3). El $\mathrm{NO}_{2}$ mostró una carga acumulada con un perfil similar al de $\mathrm{NO}_{3}$. Las diferencias entre tratamientos resultaron 

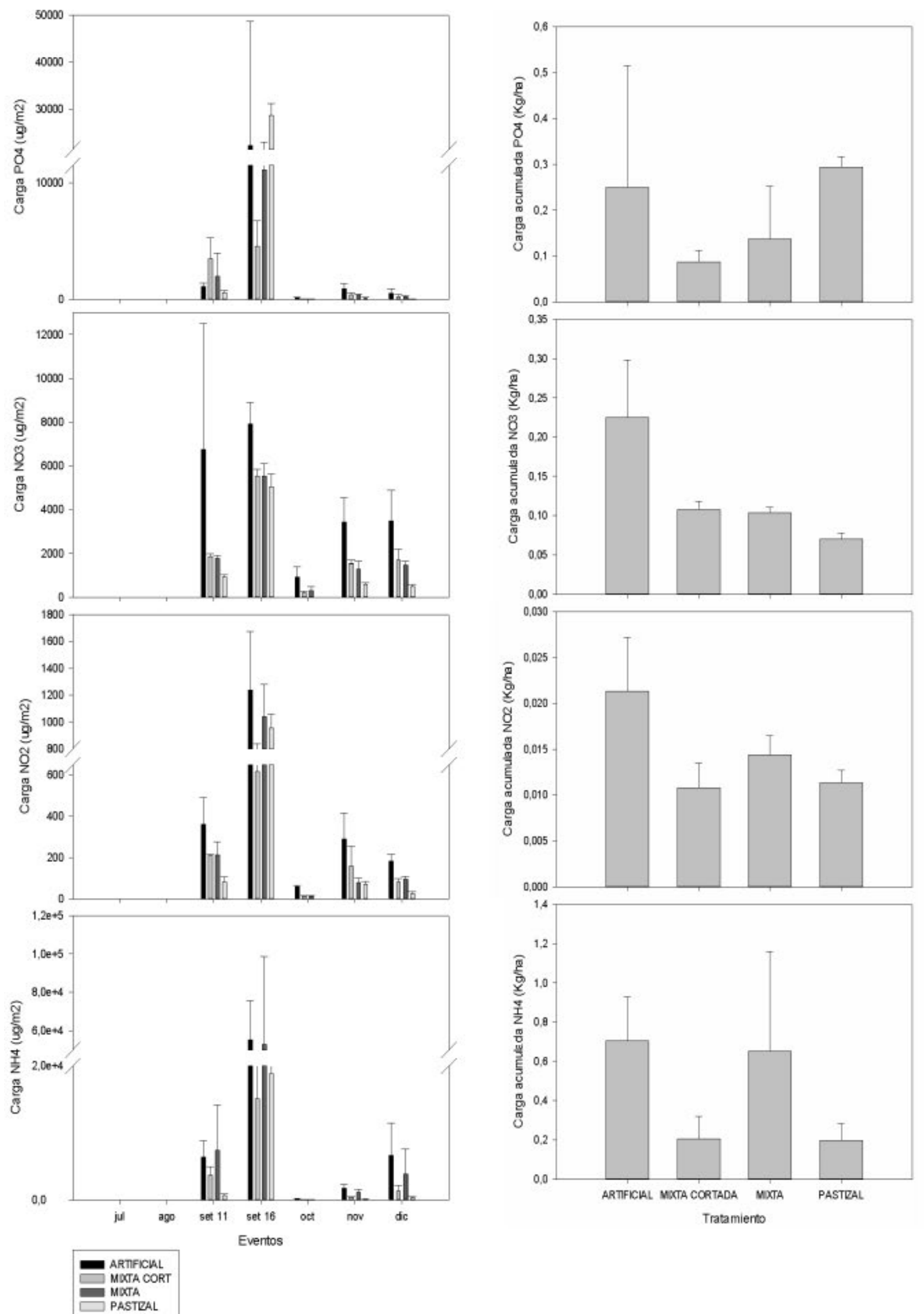

Figura 7. Carga de nutrientes disueltos para los cinco eventos de precipitación. La escorrentía se estimó con el método del NC (izquierda). Carga acumulada de nutrientes disueltos en los seis meses de estudio (derecha). 
significativas. Comparando entre pares de tratamientos, las diferencias resultaron estadísticamente significativas entre pradera artificial y mixta cortada y entre pradera artificial y pastizal. El $\mathrm{NH}_{4}$ presentó valores promedio de carga acumulada mayores en la pradera artificial que en las parcelas mixta cortada y pastizal. Las parcelas mixtas presentaron un mayor valor promedio, pero también un mayor desvío estándar (Figura 7, derecha). Las diferencias entre los cuatro tratamientos no fueron significativas.

La retención de $\mathrm{PO}_{4}, \mathrm{NO}_{3}, \mathrm{NO}_{2}$ y $\mathrm{NH}_{4}$ para el período estudiado fue de $55,53,41$ y $39 \%$, respectivamente.
En todos los casos, la mayor variabilidad de algunos tratamientos respecto al resto se debe a los datos obtenidos de concentración para los diferentes nutrientes en el evento de mayor precipitación (16 de setiembre, $89 \mathrm{~mm}$ ).

\section{Discusión}

Los valores promedio de carga de SS y nutrientes resultaron mayores para pradera artificial que para el resto de los tratamientos, e intermedios para las parcelas mixtas. Esto se

\begin{tabular}{|c|c|c|c|c|c|}
\hline Autores & Fuente de nutrientes & Vegetación ZB & Ancho ZB (m) & Pendiente (\%) & Retención (\%) \\
\hline $\begin{array}{l}\text { Abu-Zreig et al. } \\
\text { (2003) }\end{array}$ & $\begin{array}{l}\text { Simulación de lluvia } \\
\text { aplicando mezcla de } \\
\text { suelo y agua }\end{array}$ & $\begin{array}{l}\text { Raigrás, festuca y } \\
\text { especies nativas }\end{array}$ & $\begin{array}{c}2 \\
5 \\
10 \\
15 \\
\end{array}$ & $2,3,5$ & carga de PT 79 \\
\hline $\begin{array}{c}\text { Al-wadaey et al. } \\
(2012)\end{array}$ & $\begin{array}{l}\text { Lluvia en microcuencas } \\
\text { ( } 2 \text { años })\end{array}$ & Festuca & $\begin{array}{l}\text { Relación área } \\
\text { de drenaje/ } \\
\text { área de filtro: } \\
0-1.1-\underline{4.3} \%\end{array}$ & 5,5 & $\begin{array}{l}\text { V escorrentía } 79 \\
\text { carga sedim. } 84 \\
\text { carga PRS } 66 \\
\text { carga Ppart } 82\end{array}$ \\
\hline $\begin{array}{l}\text { Blanco-Canqui } \\
\text { et al. (2004) }\end{array}$ & $\begin{array}{l}\text { Simulación de lluvia } \\
\text { sobre } 8 \mathrm{~m} \text { de barbecho } \\
\text { continuo }\end{array}$ & $\begin{array}{c}\text { Festuca y } \\
\text { especies nativas } \\
\text { «Grass barriers» }\end{array}$ & 8 & 5 & $\begin{array}{c}\text { V escorrentía } 18 \\
\text { carga sedim. } 92 \\
\text { carga de } \mathrm{PO}_{4}, \mathrm{NH}_{4} \text {, } \\
\mathrm{NO}_{3}, \mathrm{PT}, \mathrm{Norgánico}_{70}\end{array}$ \\
\hline $\begin{array}{c}\text { Daniels y } \\
\text { Guilliam (1996) }\end{array}$ & $\begin{array}{c}\text { Lluvia en microcuencas } \\
\text { de uso agrícola (dos } \\
\text { años) }\end{array}$ & Festuca y riparia & $0-20$ & $4-15$ & $\begin{array}{c}\text { sedim. } 60-90 \\
\text { PT 60 } \\
\text { NT 35-60 } \\
\mathrm{NO}_{3} 50-90\end{array}$ \\
\hline $\begin{array}{l}\text { Deng et al. } \\
\text { (2011) }\end{array}$ & $\begin{array}{l}\text { Simulación de lluvia } \\
\text { aplicando mezcla de } \\
\text { agua, sedimento y } \\
\text { nutrientes }\end{array}$ & $\begin{array}{l}\text { Herbáceas } \\
\text { nativas y } \\
\text { arbustos }\end{array}$ & $\begin{array}{l}10 \\
15\end{array}$ & 2 & $\begin{array}{l}\text { V escorrentía } 86 \\
\text { carga de SS } 89 \\
\text { carga PT } 85 \\
\text { carga NT } 70\end{array}$ \\
\hline $\begin{array}{l}\text { Dillaha et al. } \\
\quad(1988)\end{array}$ & $\begin{array}{l}\text { Simulación de lluvia } \\
\text { sobre feedlot simulado } \\
\text { de } 5 \times 18 \mathrm{~m}\end{array}$ & Festuca & $\begin{array}{c}0 \\
4,6 \\
9,1\end{array}$ & $5,11,16$ & $\begin{array}{l}\text { sedim. } 81-91 \\
\text { PT 58-69 } \\
\text { NT 64-74 }\end{array}$ \\
\hline $\begin{array}{l}\text { Fogle et al. } \\
\text { (1994) }\end{array}$ & $\begin{array}{l}\text { Simulación de lluvia } \\
\text { sobre parcelas de } \\
\text { erosión de } 22 \mathrm{~m}\end{array}$ & Festuca y otros & $\begin{array}{r}4,57 \\
\underline{9,14} \\
13,72\end{array}$ & 9 & $\begin{array}{c}\text { V } 97 \\
\text { masa de atrazina } \\
99,8 \\
\mathrm{PRS} \mathrm{y} \mathrm{NO}_{3} 98 \\
\mathrm{NH}_{4} \text { y sedim. 99,7 }\end{array}$ \\
\hline Smith (1989) & $\begin{array}{l}\text { Lluvia en microcuencas } \\
\text { de uso ganadero } \\
\text { ( } 22 \text { meses })\end{array}$ & $\begin{array}{l}\text { Festuca, } \\
\text { paspalum, } \\
\text { raigrás }\end{array}$ & $10-13$ & 26 & $\begin{array}{c}\text { V escorrentía } 87 \\
\text { conc. SS } 84, \text { P part } \\
80, \\
\text { N part } 85, \text { PRS } 55, \\
\mathrm{NO}_{3} 67\end{array}$ \\
\hline $\begin{array}{l}\text { Young et al. } \\
\quad(1980)\end{array}$ & $\begin{array}{l}\text { Simulación de lluvia } \\
\text { sobre feedlot }\end{array}$ & $\begin{array}{l}\text { Maíz, festuca, } \\
\text { avena y sorgo }\end{array}$ & 36 & 4 & $\begin{array}{l}\text { V escorrentía } 67 \\
\text { sólidos } 79 \\
\text { conc. NT } 84 \\
\text { conc. PT, } \mathrm{NH}_{4} \text { y } \\
\mathrm{PO}_{4} 83\end{array}$ \\
\hline $\begin{array}{l}\text { Zhou et al. } \\
\text { (2014) }\end{array}$ & $\begin{array}{l}\text { Lluvia en microcuencas } \\
\text { con uso agrícola: } \\
\text { rotación de soja y maíz } \\
\text { (cinco años) }\end{array}$ & $\begin{array}{l}\text { Pradera nativa y } \\
\text { pastizales } \\
\text { «Grass barriers» }\end{array}$ & $37-78$ & $6-10$ & $\begin{array}{l}\text { Carga NT } 84 \\
\text { Carga PT } 90 \\
\text { Carga } \mathrm{NO}_{3} 67\end{array}$ \\
\hline
\end{tabular}

Tabla 4. Resumen de estudios previos sobre retención de nutrientes en ZB (en los casos en que se usaron varios anchos de ZB se subraya el ancho al que corresponde el porcentaje de retención mostrado en la tabla). Nitrógeno total (NT), fósforo total (PT), sólidos en suspensión (SS), fosfato $\left(\mathrm{PO}_{4}\right)$, nitrato $\left(\mathrm{NO}_{3}\right)$, nitrito $\left(\mathrm{NO}_{2}\right)$, amonio $\left(\mathrm{NH}_{4}\right)$, concentración (conc.), sedimento (sedim.), volumen (V). 
debería a un efecto directo de la fertilización en el cultivo (en el caso de los nutrientes) y también a que la asociación de pastizales aguas abajo de la pradera artificial estaría reduciendo el aporte de nutrientes proveniente del cultivo. Si bien se observó variabilidad en la eficacia de las zonas buffer para retener nutrientes, coincidiendo con observaciones anteriores (Magette, et al., 1989; Abu-Zreig, et al., 2003), las tasas de retención estimadas mostraron valores menores o cercanos al $50 \%$

Este efecto de retención se evidenció a nivel de concentración para $\mathrm{NO}_{3}$ y $\mathrm{NO}_{2}$, afectando también a la carga en cada evento y a la carga acumulada. Para el caso de $\mathrm{NO}_{3}$ y $\mathrm{NO}_{2}$ las diferencias de carga acumulada entre tratamientos resultaron estadísticamente significativas. Para SS, PT, NT, $\mathrm{NH}_{4}$ y $\mathrm{PO}_{4}$ el efecto del tratamiento no se evidenció a nivel de concentración, sino principalmente a nivel de la carga por evento y de la carga acumulada. Respecto al nivel en el que se hace evidente la retención de nutrientes, Zhou et al. (2014) encontraron alta variabilidad en la concentración de nutrientes en los distintos tratamientos, otros autores describen efectos importantes de reducción de la concentración de nutrientes por la vegetación (Deng, et al., 2011), mientras que Al-wadaey et al. (2012) no encontraron diferencias a nivel de la concentración sino a nivel de la carga de nutrientes por reducción del volumen de escorrentía.

La carga de los nutrientes analizados y SS mostró diferencias estadísticamente significativas entre tratamientos dentro de cada evento, principalmente para octubre, noviembre y diciembre. En general, las diferencias entre pares de tratamientos fueron estadísticamente significativas entre pradera artificial y parcelas mixtas (mixta cortada o mixta), entre mixtas y pastizal, y entre artificial y pastizal, no así entre mixta cortada y mixta. La retención de SS en las parcelas mixtas fue baja.

A su vez, el índice de correlación entre la concentración de SS y la de PT fue moderado, mientras que entre SS y NT fue muy bajo. En este sentido, es posible plantear que solo una pequeña parte de los nutrientes totales se encontró en forma particulada y la mayor parte estaba asociada a diferentes formas disueltas. De esta manera, el sistema retuvo fundamentalmente nutrientes disueltos y en menor medida formas particuladas. Estos resultados coinciden con los obtenidos por Goyenola et al. (2015), quienes compararon la concentración de P en diferentes arroyos de Uruguay y encontraron un alto predominio (86 \%) de formas disueltas de P, que podrían ser explicadas por la aplicación de fertilizantes a nivel superficial sin ser incorporados al suelo bajo la modalidad de siembra directa.

En las parcelas mixtas la relación área de ZB / área de drenaje fue de 1. Según Abu-Zreig et al. (2003), no solo se requiere de una relación área de drenaje/ área de $\mathrm{ZB}$ importante, sino también de una distancia mínima para la retención de partículas de distintos tamaños. Esto implicaría que es necesaria una $\mathrm{ZB}$ más ancha para la retención de $\mathrm{P}$ particulado y SS. Como ya se mencionó, el $\mathrm{P}$ se transporta mayormente unido a las partículas del suelo, principalmente a las más pequeñas. Las partículas más pequeñas del sedimento requieren de mayor distancia que las grandes para ser retenidas por la vegetación (Wilson, 1967). Para evaluar cambios en la retención de $\mathrm{P}$ particulado con distintos tratamientos, tal vez se requiera de parcelas de mayor largo de ZB. Otra posibilidad es que las parcelas de escorrentía hayan sido pequeñas para poder evidenciar importantes efectos de erosión y, por tanto, de retención de la ZB.
La carga acumulada para el período de estudio (seis meses) por la pradera artificial fue del entorno de $10 \mathrm{~kg} / \mathrm{ha}$ para NT y de $0,6 \mathrm{~kg} / \mathrm{ha}$ para PT y por el pastizal fueron de $7 \mathrm{~kg} /$ ha para NT y $0,5 \mathrm{~kg} / \mathrm{ha}$ para PT. Como una simplificación se llevaron los cálculos a una escala anual para poder comparar con los datos de exportación de nutrientes existentes en la bibliografía. Los datos obtenidos en este estudio son en general más elevados, salvo para PT en la pradera artificial (Tabla 5).

\begin{tabular}{|l|c|c|}
\hline \multicolumn{1}{|c|}{ Uso de suelo } & $\begin{array}{c}\text { NT } \\
(\mathbf{k g} / \mathbf{h a} / \mathbf{a n ̃ o})\end{array}$ & $\begin{array}{c}\text { PT (kg/ha/ } \\
\text { año })\end{array}$ \\
\hline Pradera artificial & $20^{*}$ & $1,2^{*}$ \\
Pastizal & $14^{\star}$ & $1^{*}$ \\
$\begin{array}{l}\text { Pradera artificial } \\
\text { (Reckhow, et al., 1980) }\end{array}$ & 6,92 & 1,16 \\
$\begin{array}{l}\text { Pastizal (adaptado de } \\
\text { Drewry, et al., 2006) }\end{array}$ & 1,33 & 0,24 \\
$\begin{array}{l}\text { Promedio de todos los } \\
\text { usos de suelo EEUU } \\
\text { (Harmel, et al., 2008) }\end{array}$ & 14,2 & 2,2 \\
\hline
\end{tabular}

Tabla 5. Comparación de carga de nutrientes exportada anualmente. El ${ }^{\star}$ indica los valores obtenidos en este trabajo, llevados a una escala anual.

Se requerirán estudios posteriores para precisar los valores hallados en esta investigación, con sistemas que permitan una determinación más real del volumen de escorrentía y con períodos de estudio más prolongados para capturar la variabilidad interanual.

Por otra parte, al comparar los aportes de PT de la pradera artificial y del pastizal, no hay diferencias muy marcadas. Considerando que el nivel de P Bray de estos suelos es bajo en relación a los suelos del país, particularmente el de la pradera artificial, esto podría determinar que ambos sistemas estén aportando similar cantidad de nutrientes. A pesar de estos niveles de $\mathrm{P}$, existieron diferencias en el rango bajo de intensidad de uso del suelo, por lo que es posible considerar que si este trabajo se realizara en situaciones de historia previa de uso más intensivo, las diferencias entre tratamientos hubieran sido mayores.

La capacidad de amortiguación del pastizal se vio alterada frente a eventos de alta precipitación, en los que se pudo observar que el pastizal mostró valores similares o más altos que la pradera artificial. Estos resultados coinciden con los obtenidos por Daniels y Gilliam (1996), quienes muestran reducción importante de la eficiencia de las ZB cuando las lluvias superan los $60 \mathrm{~mm}$. Esto podría deberse a que si bien normalmente el pastizal funciona como sumidero de nutrientes, frente a eventos extremos cambian las condiciones y pasa a comportarse como fuente de nutrientes por la fuerte escorrentía.

Teniendo en cuenta que los pastizales en general presentan una mayor cobertura que la pradera artificial y que el $\mathrm{P}$ se transporta mayormente unido al sedimento, se puede esperar que una mayor distancia de ZB sea más eficiente y permita evidenciar mejor los efectos de filtro. Aunque la biomasa fue mayor en diciembre para la pradera artificial que para el pastizal, la forma en que se dispone esa biomasa puede estar generando diferencias en la retención de nutrientes. La den- 
sidad del pastizal o el porcentaje de cobertura desde el nivel de suelo es un factor de gran importancia para la retención como barrera física y como promotor de infiltración (Wilson, 1967; Abu-Zreig, et al., 2003; Borin, et al., 2010). A su vez, el pastizal es una comunidad vegetal con alta diversidad en comparación con la pradera artificial. Algunos autores plantean que a mayor diversidad y mayor riqueza de especies se asocia una mayor diversidad funcional $y$, por tanto, una mayor resiliencia y estabilidad del ecosistema (Tilman y Downing, 1994; Tilman, 1996). En este sentido se puede pensar que el ecosistema de pastizal podría estar teniendo en el largo plazo un rol importante en la retención e incorporación de nutrientes que provienen de escorrentía.

Algunos autores discuten la escala de aproximación al problema. Generalmente, pequeñas parcelas de campo proveen condiciones uniformes, eliminando la heterogeneidad debida a factores topográficos, de suelo, de cobertura, de superficie y de clima, permitiendo hacer generalizaciones y modelar (Bormann, et al., 2012; Al-wadaey, et al., 2012). Otros autores argumentan que las cuencas son heterogéneas en cuanto a topografía, tipo de suelo y que, por lo tanto, algunos procesos hidrológicos importantes para el transporte de suelo y nutrientes a escala de cuencas pueden no ser evidentes a escala de parcelas, como el flujo subsuperficial, interacción entre agua superficial y profunda y fluctuación de la napa freática, así como flujos preferenciales de agua. En este sentido plantean que los resultados obtenidos sobre la eficacia de ZB a escala de parcela no necesariamente son extrapolables a escala de cuenca (Zhou, et al., 2014).

En este trabajo se adaptó una herramienta de origen agronómico para responder una pregunta de tipo ecológica, brindando una aproximación a la estimación del SE prevención de la eutrofización por parte de los pastizales. En futuros estudios se deberían tener en cuenta algunos aspectos para una mejor evaluación de la eficiencia de las ZB en la retención de nutrientes, por ejemplo: la necesidad de generar estudios de más largo plazo, incorporando la dinámica anual e interanual de la vegetación y del clima; la inclusión de parcelas de mayor longitud (mayor ancho de ZB) que permitan evidenciar efectos de retención de SS y P particulado; la generación de un mayor número de réplicas dada la alta variabilidad de respuesta a los tratamientos; la evaluación de la posibilidad de incorporar otro tipo de sistemas para obtener datos de escorrentía, y el análisis de la posibilidad de trabajar a una escala espacial mayor que incorpore aspectos que ocurren a nivel de microcuenca o de cuenca que no quedan evidenciados a nivel de parcelas.

\section{Conclusiones}

Se observó retención de nutrientes provenientes de la pradera artificial por parte del buffer de pastizales, pese a que la variabilidad en los datos fue elevada. El agregado de una ZB de pastizal aguas abajo de la pradera artificial (parcelas mixta y mixta cortada) redujo la carga acumulada promedio de SS, $\mathrm{PT}, \mathrm{NT}, \mathrm{PO}_{4}, \mathrm{NO}_{3}, \mathrm{NO}_{2}$ y $\mathrm{NH}_{4}$ respecto a pradera artificial sola. La retención fue del entorno de 40-50 \% en todos los nutrientes y de $28 \%$ en SS.

\section{Reconocimientos}

A los funcionarios de Facultad de Agronomía y Guardaparques del Paisaje Protegido Laguna de Rocha por su colabora- ción en la instalación de las parcelas de escorrentía. A Ronald Ryan, propietario del campo donde se instalaron las parcelas de escorrentía. Al Espacio Interdisciplinario de la Universidad de la República y «Sensing the Americas’ Freshwater Ecosystem Risk (SAFER) from Climate Change» Interamerican Institute for Global Change-IAI (CRN 3038) por financiar parcialmente este proyecto. A Cristina Bañobre del CURE por su colaboración en los análisis de P en suelo. A Germán Azcune del CURE por su colaboración en las medidas iniciales de nutrientes.

\section{Referencias}

Abu-Zreig, M., Rudra, RP., Whiteley, HR., Lalonde, MN. y Kaushik, NK., 2003. Phosphorus removal in vegetated filter strips. En: Journal of Environmental Quality, 32(2), pp.613619.

Aguiar, TR., Rasera, K., Parron, LM., Brito, AG. y Ferreira, MT., 2015. Nutrient removal effectiveness by riparian buffer zones in rural temperate watersheds: The impact of no-till crops practices. En: Agricultural Water Management, 149, pp.74-80.

Al-wadaey, A., Wortmann, CS., Franti, TG., Shapiro, CA. y Eisenhauer, DE., 2012. Effectiveness of grass filters in reducing phosphorus and sediment runoff. En: Water Air Soil Pollut, 223, pp.5865-5875.

American Public Health Association, 1985. Standard methods for the examination of water and wastewater. 16th ed. Washington: APHA.

Aubriot, L., Conde, D., Bonilla, S., Hein, V. y Britos, A., 2005. Vulnerabilidad de una laguna costera en una Reserva de Biosfera: indicios recientes de eutrofización. En: Vila, I. y Pizarro, J., eds. Taller Internacional de Eutrofización de Lagos $y$ Embalses CYTED XVIIB. [s.n.]: Patagonia Impresores. pp.65-85.

Bendschneider, K. y Robinson RJ., 1952. A new spectrophotometric method for determintation of nitrite in the sea water. En: Journal Marine Research, 11, pp.87-96.

Blanco-Canqui, H., Gantzer, CJ., Anderson, SH., Alberts, EE. y Thompson, AL., 2004. Grass barrier and vegetative filter strip effectiveness in reducing runoff, sediment, nitrogen, and phosphorus loss. En: Soil Science Society of America, 68, pp.1670-1678.

Borin, M., Passoni, M., Thiene, M. y Tempesta, T., 2010. Multiple functions of buffer strips in farming areas. En: European Journal of Agronomy, 32, pp.103-111.

Bormann, NLB., Baxter, CA., Andraski, TW., Good, LW. y Bundy, LG., 2012. Scale-of-measurement effects on phosphorus in runoff from cropland. En: Journal of Soil and Water Conservation, 67(2), pp.122-133.

Brazeiro, A., Achkar, M., Canavero, A., Fagúndez, C., González, E., Grela, I., Lezama, F., Maneyro, R., Barthesagy, L., Camargo, A., Carreira, S., Costa, B., Núñez, D., da Rosa, I. y Toranza, C., 2008. Prioridades geográficas para la conservación de la biodiversidad terrestre de Uruguay. Resumen ejecutivo. Montevideo: Facultad de Ciencias. (Proyecto PDT 32-26).

Cabrera, C., 2015. Optimización de usos del suelo para prevenir floraciones nocivas de fitoplancton en la Laguna de Rocha, Uruguay. Montevideo: Facultad de Ciencias. (Tesis de Maestría).

Carpenter, SR., Stanley, EH., y Vander Zanden, MJ., 2011. State of the world's freshwater ecosystem physical, chemical, and 
biological changes. En: Annual Review of Environment and Resources, 36, pp.75-99.

Carpenter, SR., 2005. Eutrophication of aquatic ecosystems: biostability and soil phosphorus. En: Proceedings of the National Academy of Sciences, 102 (29), pp.10002-10005.

Daniels, RB. y Gilliam, JW., 1996. Sediment and chemical load reduction by grass and riparian filters. En: Soil Science Society of America, 60, pp.246-251.

Deng, N., Li, H. y Shi, D., 2011. Preliminary experimental study on effectiveness of vegetative filter strips to polluentes in surface runoff. En: Journal of Water Resource and Protection, 3, pp.222-227.

DIEA, 2014. Anuario estadístico agropecuario 2014. Montevideo: DIEA.

Dillaha, TA., Sherrard, JH., Lee, D., Mostaghimi, S. y Shanholtz, VO., 1988. Evaluation of vegetative filter strips as best management practice for feed lots. En: Journal Water Pollution Control Federation's, 60, pp.1231-1238.

Drewry, JJ., Newham, LTH., Greene, RSB., Jakeman, AJ. y Croke, BFW., 2006. A review of nitrogen and phosphorus export to waterways: context for catchment modelling. En: Marine and Freshwater Research, 57, pp.757-774.

Ernst, O. y Siri-Prieto, G., 2011. La agricultura en Uruguay: su trayectoria y consecuencias. En: Facultad de Agronomía, 2011. Segundo Simposio Nacional de Agricultura de Secano. [s.l.]: Facultad de Agronomía. pp.149-163.

Fabiano, G. y Santana, O., 2006. Las pesquerías en las lagunas costeras salobres de Uruguay. En: Menafra, R, RodríguezGallego, L, Scarabino, F y Conde, D., ed., 2006. Bases para la conservación y el manejo de la costa uruguaya. Montevideo: Vida Silvestre. pp.557-565.

Fogle, AW., Carey, DI., Barfield, BJ., Blevins, RL., Evangelou, VP., Madison, CE., y Inamdar, SP., 1994. Impact of riparian grass filter strips on surface-water quality. Lexington: University of Kentucky. (Information Circular, 46).

Goyenola, G., Meerhoff, M., Teixeira-de Mello, F., GonzálezBergonzoni, I., Graeber, D., Fosalba, C., Vidal, N., Mazzeo, N., Ovesen, NB., Jeppesen, E. y Kronvang, B., 2015. Monitoring strategies of stream phosphorus under contrasting climate-driven flow regimes. En: Hydrology and Earth System Science, 19, pp.4099-4111.

Harmel, D., Qian, S., Reckhow, K. y Casebolt, P., 2008. The MANAGE database: nutrient load and site characteristic updates and runoff concentration data. En: Journal of Environmental Quality, 37, pp.2403-2406.

Hoffman, CC., Kjaergaard, CH., Uusi-Kämppä, J., Hansen, HC. y Kronvang, B., 2009. Phosphorus retention in riparian buffers: review of their efficiency. En: Journal of Environmental Quality, 38, pp.1-14.

Instituto Nacional de Estadística, 2011. Censos 2011. Población por grupo decenal de edades, según área, localidad y sexo [En línea]. [Consulta 29 de junio de 2017]. Disponible en: http://www.ine.gub.uy/web/guest/censos-2011

Jeppesen, E., Kronvang, B., Meerhoff, M., Søndergaard, M., Hansen, KM., Andersen, HE., Lauridsen, TL., Liboriussen, L., Beklioglu, M., Özen, A. y Olesen, JE., 2009. Climate change effects on runoff, catchment phosphorus loading and lake ecological state, and potential adaptations. En: Journal Environmental Quality, 38, pp.1930-1941.

Koroleff, F., 1970. Direct determination of ammonia in natural water as indophenol-blue. En: ICES. International Conference in the Exploration of the Sea. Information on techniques and methods for sea water analysis. C.M. 1969/
C9. Copenhagen: ICES. (Interlaboratory Reports 3). pp.19-22.

Lowrance, R., Todd, R., Fail, J., Hendrickson, O., Leonard, R. y Asmussen, L., 1984. Riparian forest as nutrient filters in agricultural watersheds. En: BioScience, 34(6), pp.374-377.

Magette, WL., Brinsfield, RB., Palmer, RE. y Wood, JD., 1989. Nutrient and sediment removal by vegetated filter strips. En: Transactions of the ASAE, 32(2), pp.663-667.

McDowell, RW. y Sharpley, AN., 2001. Approximating phosphorus release from soils to surface runoff and subsurface drainage. En: Journal of Environmental Quality, 30, pp.508-520.

MGAP, 1976. Carta de reconocimiento de suelos del Uruguay. Montevideo: MGAP

Millennium Ecosystem Assessment , 2003. Ecosystems and human well-being: a framework for assessment. Washington: Island Press. (Millennium Ecosystem Assessment Series).

Moss, B., Kosten, S., Meerhof, M., Battarbee, R., Jeppesen, E., Mazzeo, N., Havens, K., Lacerot, G., Liu, Z., De Meester, L. y Paerl, H., 2011. Allied attack: climate change and eutrophication. En: Inland Waters, 1(2), pp.101-105.

Müller, R. y Widemann, O., 1955. Die bestimmung des nitrations in Wasser. En: Von Wasser, 22, pp.247.

Murphy, J. y Riley, JP., 1962. A modified single solution method for the determination of phosphate in natural waters. En: Analytica Chimica Acta, 27, pp.31-36.

Naiman, RJ., Décamps, H. y McClain, ME., 2005. Riparia. Ecology, conservation, and management of streamside communities. New York: Elseiver, Academic Press.

Nin, M., Soutullo, A., Rodríguez-Gallego, L., y Di Minin, E., 2016. Ecosystem services-based land planning for environmental impact avoidance. En: Ecosystem Services, $17, \mathrm{pp} .172-184$

Osborne, LL. y Kovacic, DA., 1993. Riparian vegetated buffer strips in water-quality restoration and stream management. En: Freshwater Biology, 29, pp.243-258.

Perdomo, CH., Barreto, P. y Piñeiro, V., 2015. Pérdida de fósforo desde suelos agrícolas hacia aguas superficiales: resultados preliminares para Uruguay y posibles medidas de manejo para mitigar riesgos. En: Facultad de Agronomía. IV Simposio Nacional de Agricultura. Paysandú, Uruguay (28-29 de octubre de 2015). Paysandú: Facultad de Agronomía. pp.77-94.

Peterjohn, WT., y Correll, DL., 1984. Nutrient dynamics in an agricultural watershed: observations on the role of a riparian forest. En: Ecology, 65(5), pp.1466-1475.

Pote, DH., Daniel, TC., Sharpley, AN., Moore, PA., Edwards, DR. y Nichols, DJ., 1996. Relating extractable soil phosphorus losses in runoff. En: Soil Science Society of America, 60, pp.855-859.

Reckhow, KH., Beaulac, M. y Simpson, J., 1980. Modeling phosphorus loading and lake response under uncertainty: a manual and compilation of export coefficients. Washington: U.S. Environmental Protection Agency. (EPA 440/5-80-011).

Rodríguez-Gallego, L., Meerhoff, E., Clemente, JM. y Conde, D., 2010. Can ephemeral proliferations of submerged macrophytes influence zoobenthos and water quality in coastal lagoons? En: Hydrobiología, 646(1), pp.253-269.

Rodríguez-Gallego, L., Sabaj, V., Masciadri, S., Kruk, C., Arocena, R. y Conde, D., 2015. Salinity as a major driver for submerged aquatic vegetation in coastal lagoons: a 
multi-year analysis in the subtropical Laguna de Rocha. En: Estuaries and Coasts, 38(2), pp.451-465.

Rodríguez-Gallego, L., Achkar, M., Defeo, O., Vidal, L., Meerhoff, E. y Conde, D., 2017. Effects of land use changes on eutrophication indicators in five coastal lagoons of the Southwestern Atlantic Ocean. En: Estuarine, Coastal and Shelf Science, 188, pp.116-126.

Sabater, S., Butturini, A., Clement, JCh., Burt, T., Dowrick, D., Hefting, M., Mattre, V., Pinay, G., Postolache, C., Rzepecki, M. y Sabater, F., 2003. Nitrogen removal by riparian buffers along a european climatic gradient: patterns and factors of variation. En: Ecosystems, 6, pp.20-30.

Sharpley, AN., Gburek, WJ., Folmar, G. y Pionke, HB., 1999. Sources of phosphorus exported from an agricultural watershed in Pennsylvania. En: Agricultural Water Management, 41, pp.77-89.

Sharpley, AN., Daniel, T., Sims, T., Lemunyo, J., Stevens, R. y Parry, R., 2003. Agricultural phosphorus and eutrophication. [s.l.]: Agricultural Research Service, USA.

Sharpley, AN., 2015. Agricultural phosphorus and water quality: challenges to science, practice, and policy. En: Facultad de Agronomía. IV Simposio Nacional de Agricultura. Paysandú, Uruguay (28-29 de octubre de 2015). Paysandú: Facultad de Agronomía. pp.49-75.

Smith, CM., 1989. Riparian pasture retirement effects on sediment, phosphorus, and nitrogen in channellised surface run-off from pastures. En: New Zeland Journal of Marine and Freshwater Research, 23, pp.139-146.
Sondergaard, M., Jenses, JP. y Jeppensen, E., 2001. Retention and internal loading of phosphorus in shallow, eutrophic lakes. En: The Scientific World, 1, pp.427-442.

Tilman, D., 1996. Biodiversity: Population versus ecosystem stability. En: Ecology, 77(2), pp.350-363.

Tilman, D. y Downing, J., 1994. Biodiversity and stability in grasslands. En: Nature, 367, pp.363-365.

USDA, 1985. SCS national engineering handbook. Washington: USDA

Vadas, PA., Kleinman, PJA., Sharpley, AN. y Turner, BL., 2005. Relating soil phosphorus to dissolved phosphorus in runoff: a single extraction coefficient for water quality modeling. En: Journal of Environmental Quality, 34, pp.572-580.

Valderrama, JC., 1981. The simultaneous analysis of total $\mathrm{N}$ and $\mathrm{P}$ in natural waters. En: Marine Chemistry, 10, pp.109-122.

Wilson, LG., 1967. Sediment removal from flood water by grass filtration. En: Transactions of the American Society of Agricultural Engineers, 10(1), pp.35-37.

Young, RA., Huntrods, T. y Waine, A., 1980. Effectiveness of vegetated buffer strips in controlling pollution from feedlot runoff. En: Journal of Environmental Quality, 9, pp.483-487.

Zar, JH., 1999. Biostatistical analysis. New Jersey: Prentice Hall. Zhou, X., Helmers, MJ., Asbjornsen, H., Kolka, R., Tomer, MD. y Cruse, RM., 2014. Nutrient removal by prairie filter strips in agricultural landscapes. En: Journal of soil and water conservation, 69(1), pp.54-64. 